\title{
English Teachers Professional Development Needs for Web Development Skills: Meeting the Challenges of Teaching English Language in the Information Age
}

\author{
Sani Alhaji Garba
}

Department of Educational Foundations, Faculty of Technology Education, Abubakar Tafawa Balewa University (ATBU) Bauchi, Nigeria

Email: sanialhajigarba@yahoo.com

Received: January 25, $2017 \quad$ Accepted: March 2, $2017 \quad$ Online Published: $\quad$ March 20, 2017

\begin{abstract}
Utilizing the resources of the web in educational practices has made instructional processes more efficient and interesting and has made the learning process on the other hand much easier and attractive. With the web, English language teachers now have the option of engaging learners in online (web-based) instructions in addition to the use of conventional classroom instructions or alternatively the use of a blended approach. Effective use of the web for instructional purposes requires basic knowledge of web design and development using HTML (Hyper Text Markup Language), CSS (Castigating Style Sheet), JS (JavaScript), Content Management Systems (CMS), and Adobe Software package for web design. Thus, teachers' professional development needs to be redirected toward providing this knowledge and skills. Providing teachers with these technological skills would help them in acquiring the competence needed in designing and developing instructional websites that suites their peculiar pedagogical and content needs for effective teaching and learning using the web. This article examines the contemporary knowledge and skills needed by teachers in general and English language teachers in particular to effectively use the web for instructional purposes and how such needed knowledge and skills can be developed through teacher professional development programs and pre-service teacher training for good practice.
\end{abstract}

Keywords: web development, instructional website, hypertext markup language, castigating style sheet, javascript, content management system

\section{Introduction}

The information age is characterized with an increasing engagement of people in the use of computer, internet, and the World Wide Web for various reasons (Castells, 2004). People are becoming more and more reliant on the use of the web in search of information for leisure, business, and education (Mikre, 2011). It has provided for its users variety of options for all kinds of information making it a free platform of accessing and verifying information (Proctor, 2005). Students spent a great deal of time on the web mostly for social reasons (Anderson, 2001). Should such time of the student engagement with the web for social reasons be redirected to engagement with instructional websites for interactive educational activities it would make a great deal of difference in their educational career (Schaaf, 2012). This would require the design and development of customized interactive instructional websites that are subject-based. Such desired interactive instructional website should be used by teachers to engage their students in teaching-learning activities (Grant \& Basye, 2014).

Developing good instructional websites by teachers would require teachers to have additional technological skills and competence. The additional technological skills needed by teachers as identified and discussed in this article need to be integrated to form part of the curriculum for teacher education and training. For English teachers to meet up with emerging challenges of handling $21^{\text {st }}$ century learner's need (who are often described as 'Digital Natives') English teachers need to be competent in the design and development of good instructional websites for their students (Turner, 2005); such technological knowledge and skills needed by teachers include knowledge and skills of using Hyper Text Markup Language (HTML), Castigating Style Sheet (CSS), JavaScript (JS), Content Management System (CMS), and knowledge of principles of effective instructional websites. Few of the technological knowledge and skills needed 


\section{International Journal of Research in English Education}

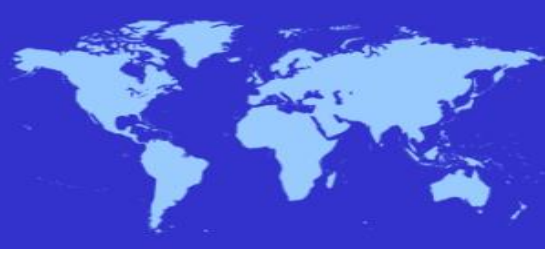

by the teacher as listed above (HTML, JavaScript, Castigating Style Sheet, and Content Management System in particular) are explained later in this article as they relate to teacher professional development and practice.

However, acquiring these knowledge and skills alone may not be enough. Teachers may need to develop further the art and skills of blending these knowledge and skills with their existing knowledge of pedagogy and subject content. The interplay of the three domains of knowledge is what teachers need to know and apply in the teaching-learning process.

\section{The Need for Knowledge and Skills of Using HTML, JavaScript, CSS, and CMS}

Websites are made up of one or more web pages. The content of a web page may be text, images, videos, or a combination of all the three. The process of designing and developing a website requires knowledge and skills of using HTML, CSS, and JavaSacript. In the present era of information technology, the continuous integration of ICT in educational practices is necessitating the need for the development and use of instructional websites in the process of teaching and learning. Thus teachers need to have basic knowledge and skills of web design and development for them to be able to design and develop effective instructional websites that can facilitate teaching and learning. Teachers therefore need to have knowledge and skills of using HTML, CSS, and JavaScript.

\subsection{Knowledge of HTML}

Hyper Text Markup Language (HTML) is a language of the web that is understood by the web browsers of a computer and other internet enabling devices. It is used in writing the text content of a web page. The language is made up of 'Tags', 'Attributes' and 'Elements.' HTML script for web pages content is usually written in the 'Notepad Window Environment' of your computer. Though the scope of the content of this paper is not intended to teach the reader how to use HTML, CSS, or JavaScript; but we consider it important to demonstrate simply how the three (HTML,CSS, and JavaScript) are used in writing, designing, and presenting the content of a web page for an example. This we believe would help the reader who is likely to have very little or no knowledge of the three web languages to appreciate the need for teachers to acquire knowledge and skills of the three web languages of the computer. It would help teacher education curriculum planners and developers to see the need of incorporating these knowledge and skills in teacher education curriculum design.

There are two ways of going to the Notepad window from the desktop environment of your computer. You can click on the start button situated at the left end of the bottom bar of the desktop environment of your computer (see figure 1 , the start button is circled in red color lines).

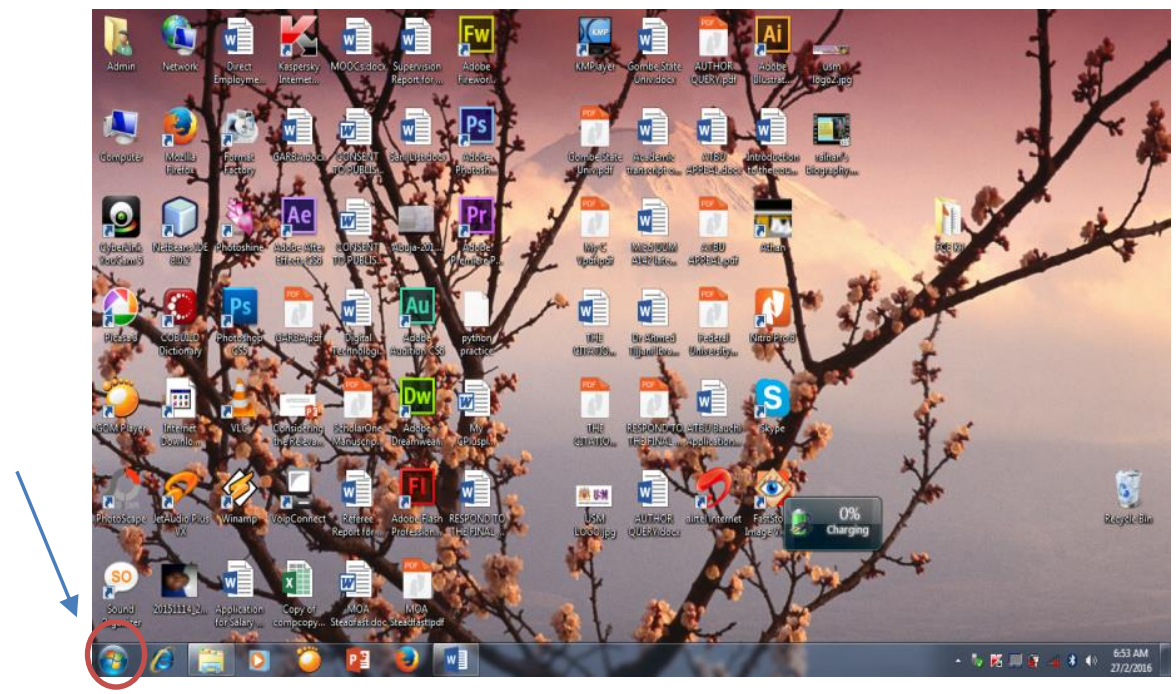

Figure 1

Once you click on the pointed area highlighted in red circle in the image above, a pop up menu would appear as shown in figure 2; then click on 'All Program' (it is the last item in the pop menu-indicated with a red square). 


\section{International Journal of Research in English Education}
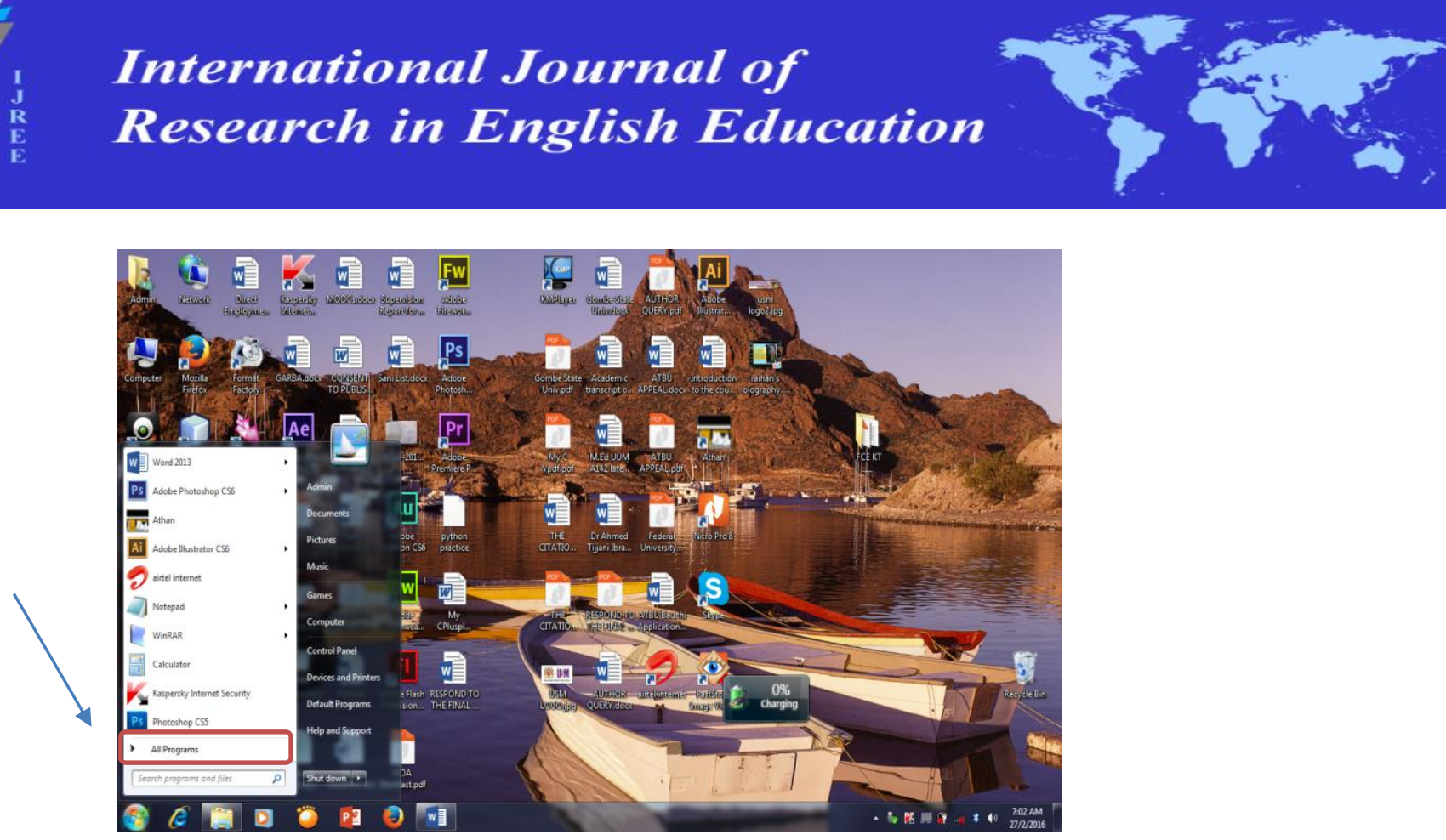

Figure 2

Clicking on the indicated area (all programs) in figure 2 above would display the menu for all the programs in your computer as shown in figure 3, scroll down the menu to select and click on 'Accessories.' By clicking on the accessories a pop up menu for all the available accessories in your computer would appear (see figure 4); then, scroll down the menu to locate and click on Notepad and the system would navigate you to the Notepad environment as shown in figure 4.

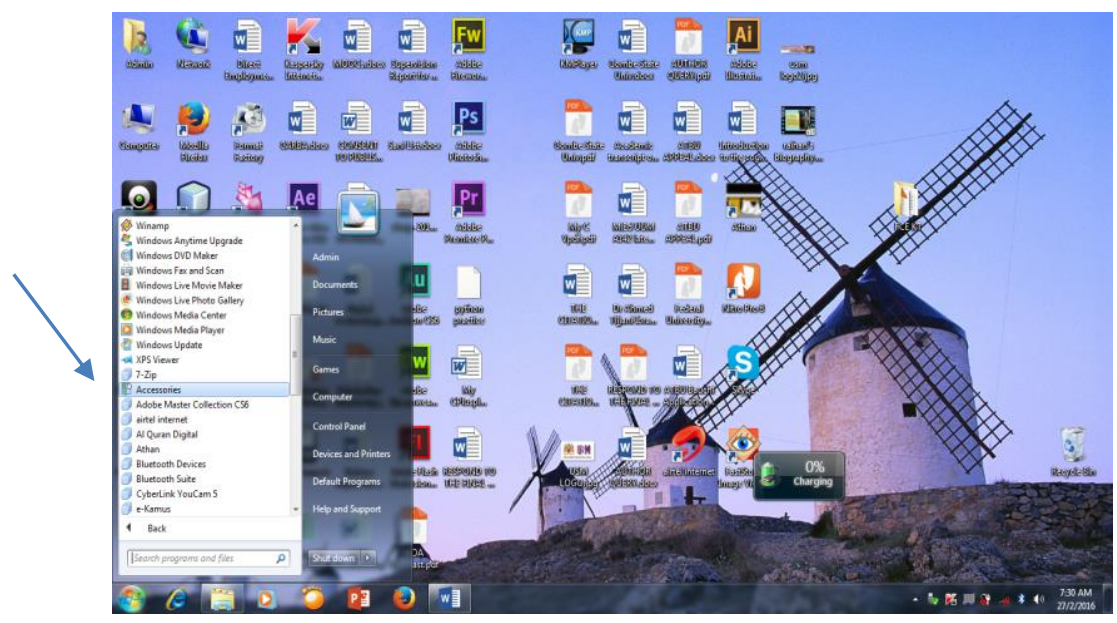

Figure 3 


\section{International Journal of Research in English Education}

keyed into the Notepad, select and click on 'file' in the top menu bar of the Notepad window; a drop down menu would pop up (see figure 7), drop down the menu to select and click on 'Save As.' Once you click on 'Save As' the save as window would pop up where you can give your html document file a name and save. It is important to note that whatever name you choose to give your document you need to add dot html (.html) at the end. We are given this document the name 'ATBU LOCATION.html' as you can see in figure 7.

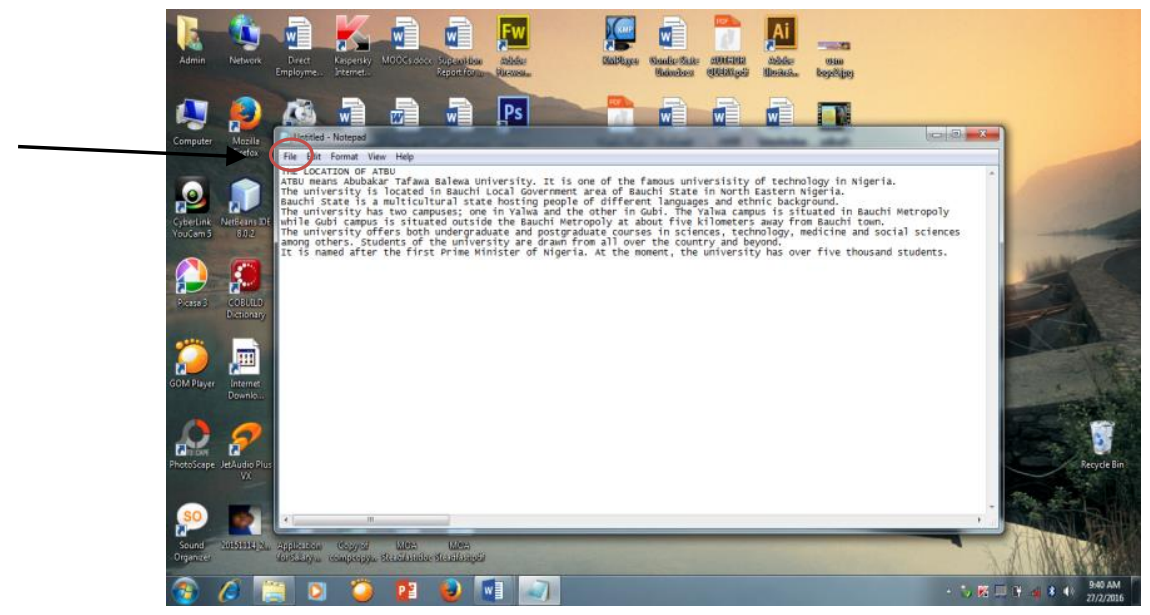

Figure 6

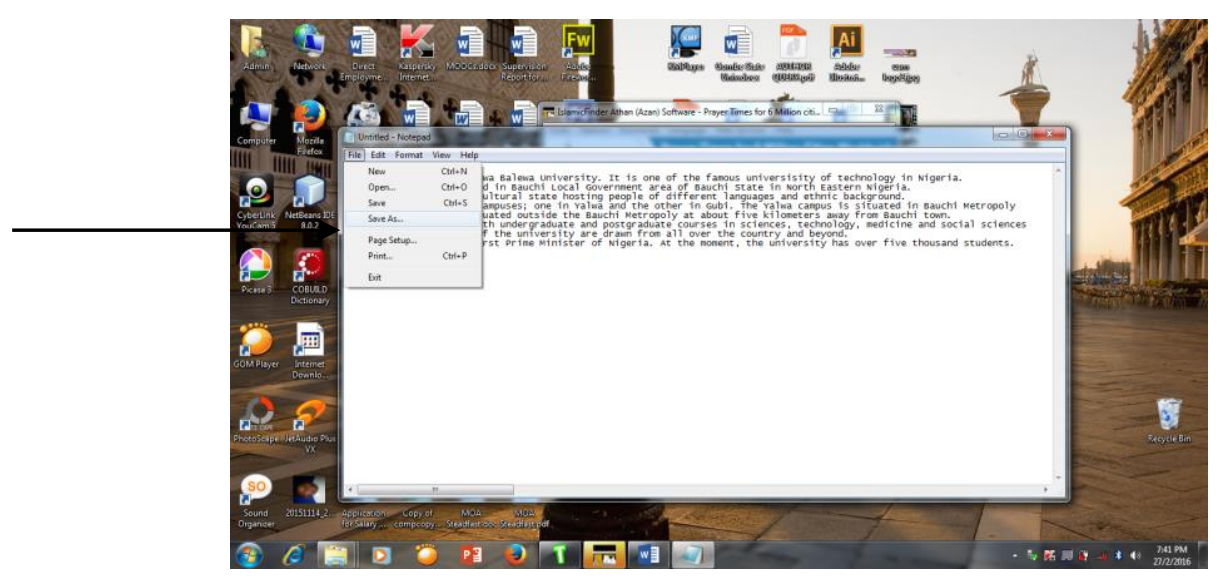

Figure 7 


\section{International Journal of Research in English Education}

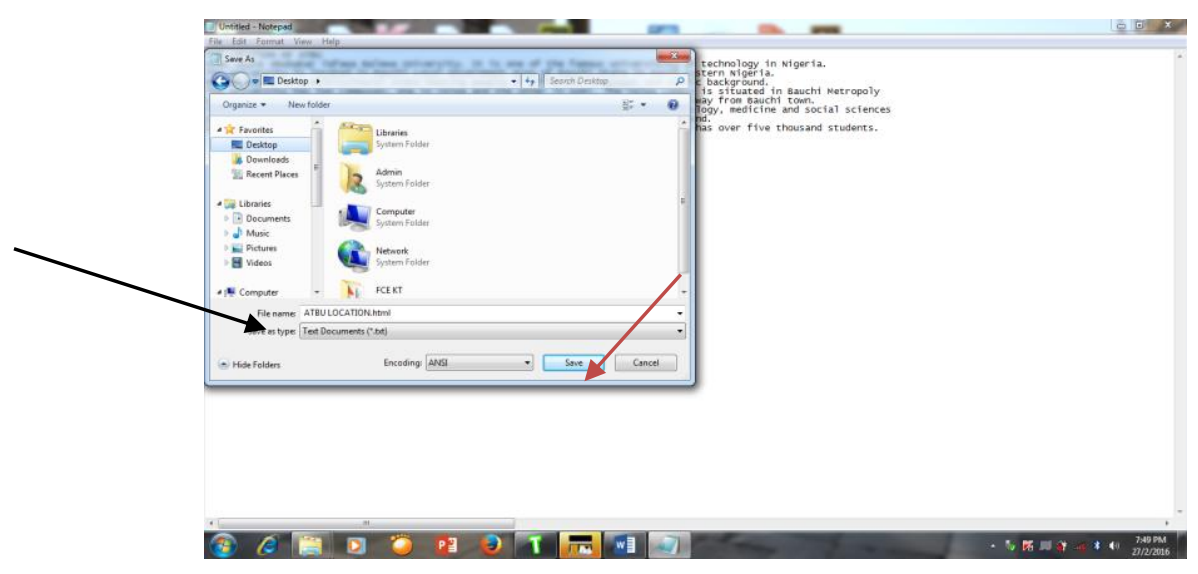

Figure 8

Once you gave your file a name you would need to select the location to save your document then click on the save button indicated with a red arrow in the image above (figure 8). We choose to save our file document in the desktop environment. Our system would save the file as a web browser document as shown in figure 9 .

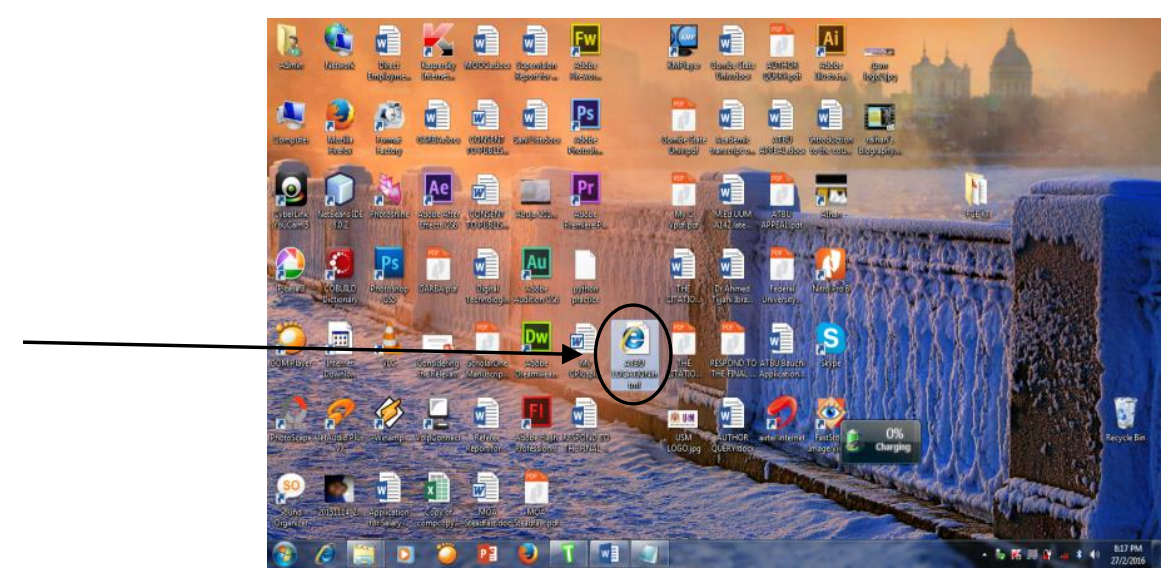

Figure 9

You can double click on the file icon to open and view how your web browser understood and interprets the content of your html script. You would notice that your browser opens the file as a web document showing the content in one paragraph as shown in figure 10 instead of showing a two paragraph document with a heading in blue font. 

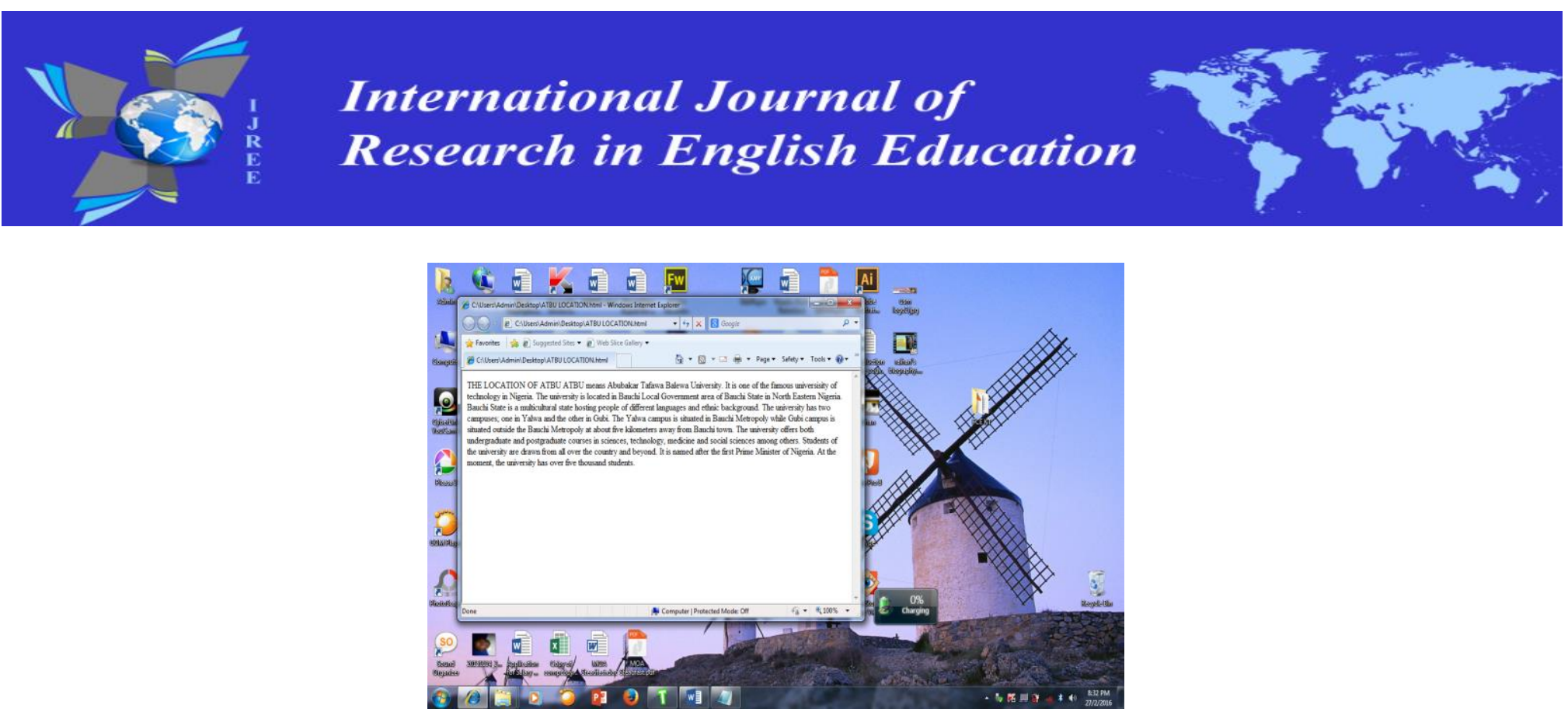

Figure 10

The browser red it as such because we did not use the Hyper Text Markup Language code that is made up of tags, attributes, and elements. Using the html code in writing the script of the text of a web page helps the computer browser to make a meaning out of the text script. To make the content appears as we want it in two paragraphs with it heading, we need to use the html default code, title element, and heading and paragraph elements codes. To do this we need to open the HTML script file in the Notepad environment; click on all programs, scroll down to select and click on accessories, scroll down the menu of the accessories to locate and click on Notepad. Then click on file, select, and click on 'open'; a window will pop up write the name of your file (ATBU LOCATION.html) in the space for file name, then click the open button (see figure 11) your html scrip file would open as shown figure 12.

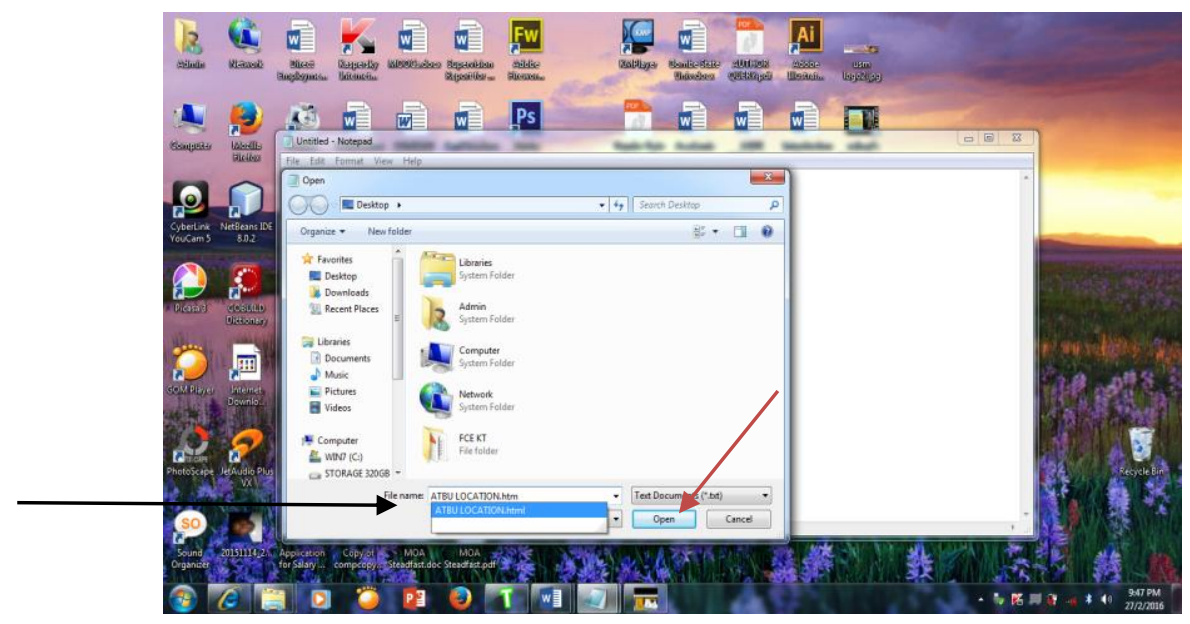

Figure 11 


\section{International Journal of Research in English Education}

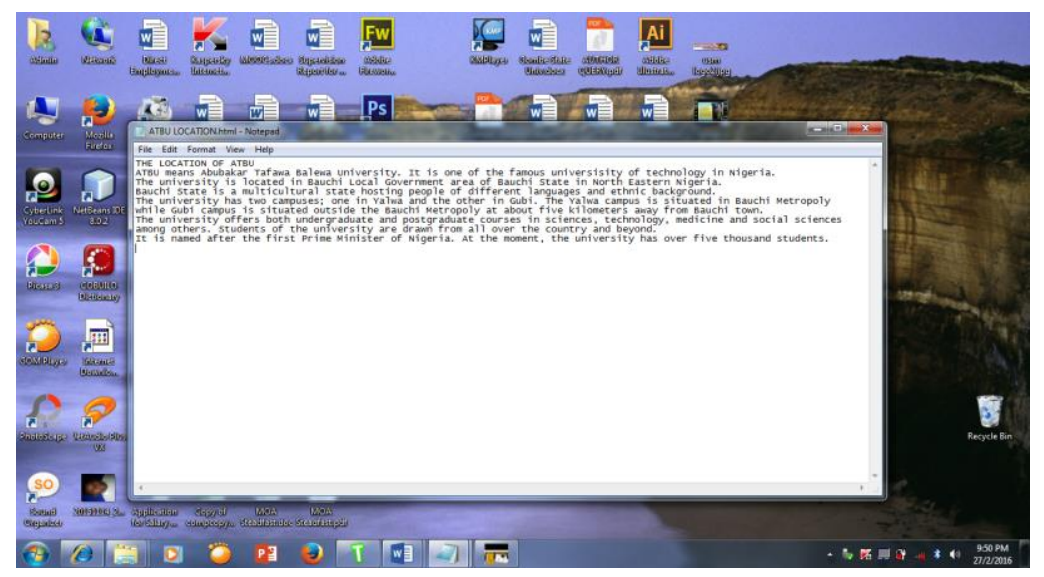

Figure 12

You can now add the needed html default code, title element, heading and paragraph elements for the document to appear as desired in two paragraphs with a heading. You would need to start your script by first writing the html default code in the first seven lines:

$<$ ! DOCT
$<$ html $>$
$<$ Head $>$
$</$ head $>$
$<$ body $>$
$</$ body $>$
$</$ html $>$

The first line is the declarative code indicating that HTML5 would be used in writing the script and the second line is the opening tag for a html document that helps the browser know that the script is a html document. The third and the fourth line has the opening and closing tags for the heading of the content of the web page and in between the two is where you write the title of the heading. Line five and six are the opening and closing tags for the main content of the web page and in between them you write the main content of the web page. Our script should therefore look like this:

$<$ ! DOCTYPE $>$

$<$ html $>$

$<$ Head $>$

$<$ title>ATBU LOCATION</title>

$<$ h1 $>$ ATBU LOCATION $</$ h1 $>$

$</$ head $>$

$<$ body $>$

$<$ P $>$ ATBU means Abubakar Tafawa Balewa University. It is one of the famous universities of technology in Nigeria. The university is located in Bauchi Local Government area of Bauchi State in North Eastern Nigeria. Bauchi State is a multicultural state hosting people of different languages and ethnic background. The university has two campuses; one in Yalwa and the other in Gubi. The Yalwa campus is situated in Bauchi Metropoly while Gubi campus is situated outside the Bauchi Metropoly at about five kilometers away from Bauchi town $</ \mathrm{P}>$.

$<p>$ The university offers both undergraduate and postgraduate courses in sciences, technology, medicine, and social sciences among others. Students of the university are drawn from all over the country and beyond. It is named after the first Prime Minister of Nigeria. At the moment, the university has over five thousand students $</ \mathrm{p}>$. 


\section{International Journal of Research in English Education}

$</$ body $>$

$</$ html $>$

The content is now coded in html. We would now write the content of the script as it is above coded into the Notepad environment to replace what we earlier have (see figure 13).

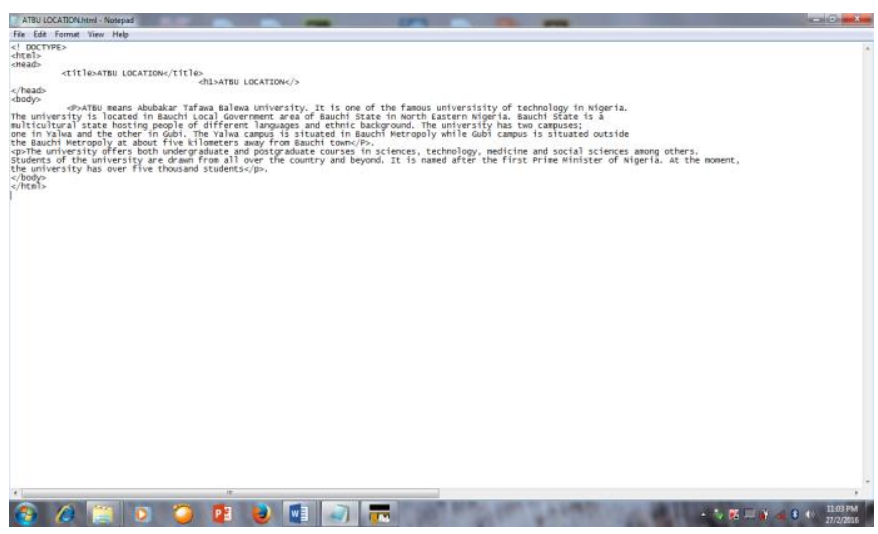

Figure 13

Click on file and scroll down to select and click on 'save' to save the changes made and close the Notepad window. Now that the changes are saved, look for the web browser file in the desktop environment where it was placed and open it. The content to be displayed as a web document would appear as desired in two paragraphs with a heading (see figure 14).

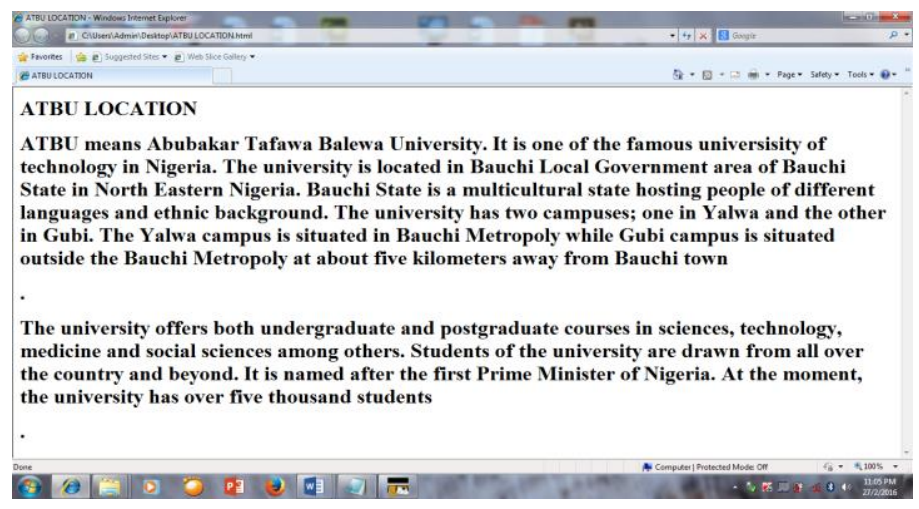

Figure 14

As you can see in figure 14 above, the content of the web document appears as desired because the Hyper Text Markup Language code helps the browser to get a full meaning of what you intend to have as the output of your html script. HTML is therefore a language of the web that helps the web browser to make a meaning out of web pages script files. The intent of this work as earlier pointed is not to teach HTML, CSS, or Java Script but to demonstrate how they work in an attempt to justify the need for their inclusion in teacher education and training.

\subsection{Knowledge of JavaScript (JS)}

JavaScript is one of the client-side web scripting languages used in creating and developing the content of web pages alongside HTML and CSS languages. HTML is a language used in writing the text content of web pages that can be 


\section{International Journal of Research in English Education}

understood and interpreted by web browsers; CSS on the other hand is a computer language that is used in designing and developing how the content of web pages written in HTML is to be presented to web clients' browsers. Java Scripting language is used in making the presentation of web pages more interactive, lively, and interesting. It should be noted that the content of web pages (numerical data, text, and images) are to be written using the HTML codes; the presentation of the content in CSS codes (applied to the HTML file) while the interactivity and dynamism of the web pages in JS codes (also applied to the HTML file).

JavaScript can be written and applied to HTML web pages basically in three (3) different ways: Inline, Internal, and External applications methods. Because of space constrain, we shall only be demonstrating how the inline application works.

\subsection{The Inline Application of JavaScript in HTML Web Pages}

In this approach, the JavaScript code to be applied should be written inside the HTML tag. For example, the image below (figure 15) shows a HTML Script without any CSS and JavaScript codes applied.

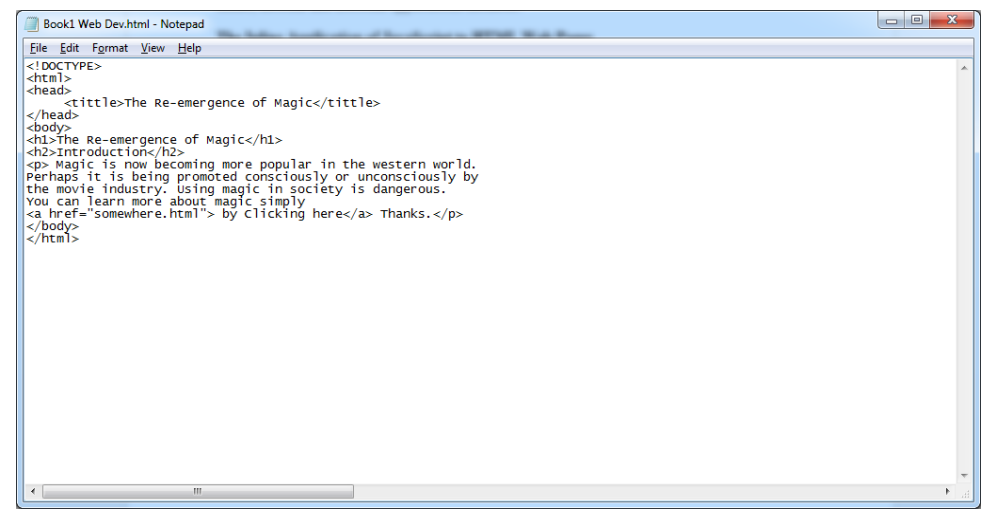

Figure 15

If you open the above html script (figure 15) in a web browser, it will display what you see in figure 16 below.

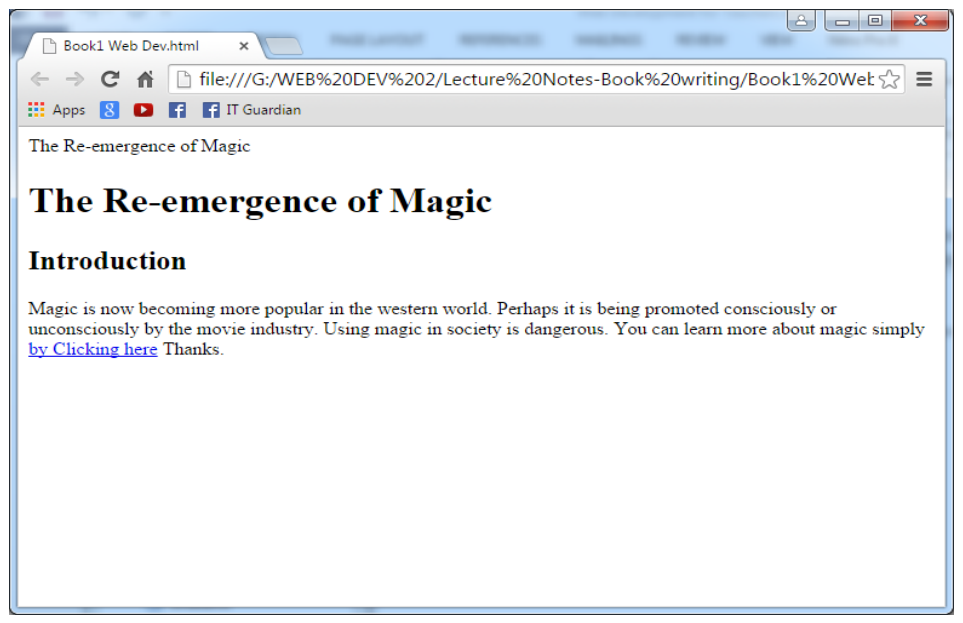

Figure 16

By clicking on the hyperlink (the blue highlighted area) you would navigate directly to the linked page. We are now going to add some JavaScript code to the HTML script (presented in figure 15) using the Inline Application method. 


\section{International Journal of Research in English Education}

We want to create a pop up warning alert for clients who wish to click on the hyperlink created in the html script; thus, if the client click on the hyperlink a warning alert pop up appears instead of navigating to the linked page. To do this using the Inline Application method we simply need to write the JavaScript code for the warning alert inside the hyperlink tag. See figure 17 below, the content of the html script presented in figure 15 is represented with the hyperlink element highlighted in red font. We shall be adding the inline JavaScript code in the hyperlink area indicated in red font.

But before we proceed to that, open a new file in your notepad, copy the html script content presented in figure 17 and key them into the new file; then save it with a name you desire and add dot html (.html) to the name given. Look for the same file again (it would now be a web browser file carrying the symbol of your web browser) double click on it to open; if you key in correctly, your web browser will display what is presented in figure 16. If you got it right and you have what is in figure 16 on your browser screen; click on the link to see what happened! You may have noticed that you have navigated immediately after clicking but to nowhere. This is because your browser can not find the referred file name being linked to. If you want to navigate to a destination you can replace the destination address used ("somewhere.html") with any valid html file name or an existing web address.

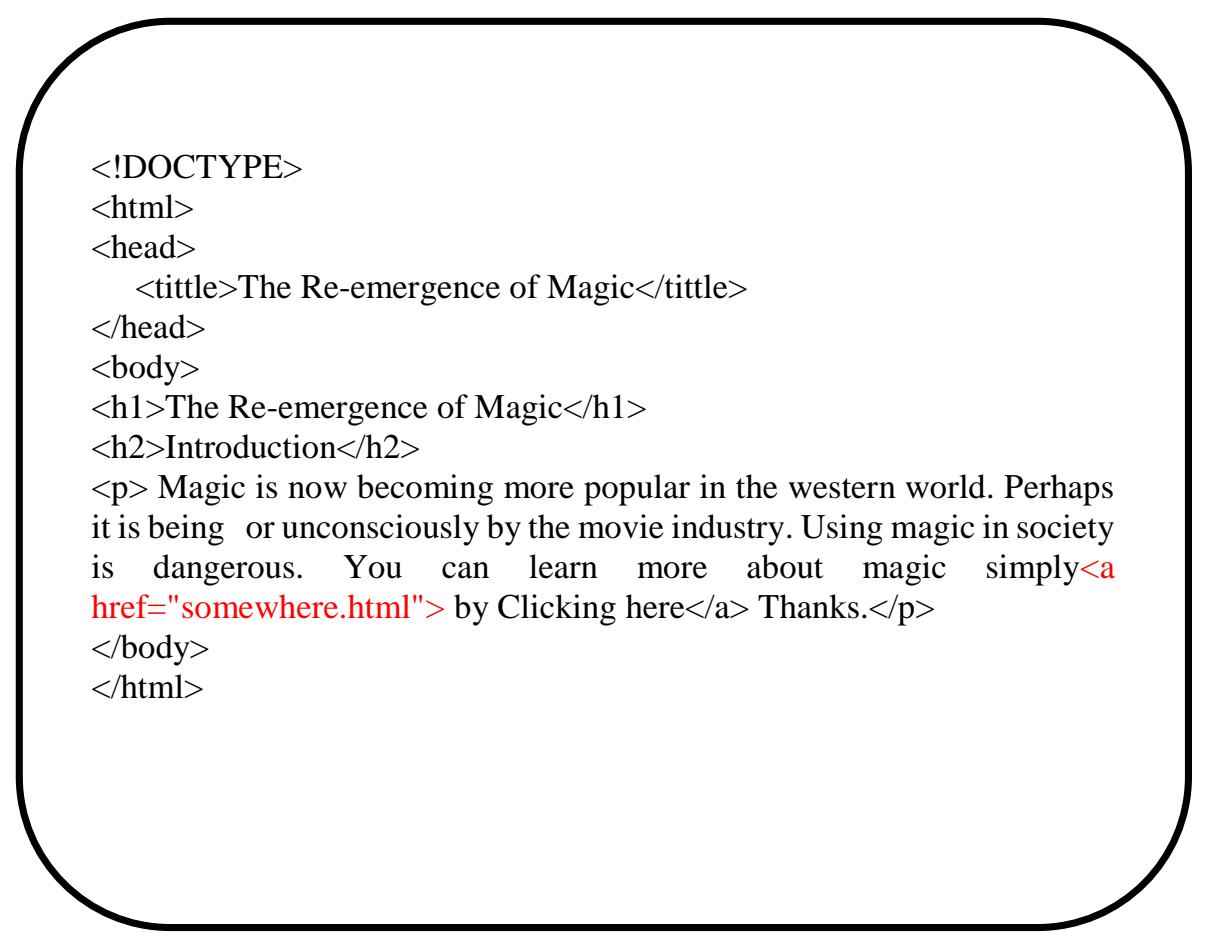

Figure 17

In figure 18, the Inline JavaScript code is added in the opening tag of the hyperlink element. The code highlighted in green font is the added code of JavaScript Inline application. 


\section{International Journal of Research in English Education}

\section{$<$ !DOCTYPE $>$}

$<$ html $>$

$<$ head $>$

$<$ tittle>The Re-emergence of Magic</tittle>

$</$ head $>$

$<$ body $>$

$<$ h1 $>$ The Re-emergence of Magic $</$ h1 $>$

$<$ h2 $>$ Introduction $</ \mathrm{h} 2>$

$<\mathrm{p}>$ Magic is now becoming more popular in the western world. Perhaps

it is being or unconsciously by the movie industry. Using magic in society

is dangerous. You can learn more about magic simply<a href="somewhere.html" onclick="alert('you are warned! it is dangerous.

Do you want to continue?');" $>$ by Clicking here $</$ a $>$ Thanks. $</$ p $>$

$</$ body $>$

$</$ html $>$

Figure 18

Add same as shown in figure 18 to your html script file and save. Then open the web browser file; the web browser will display same as shown in figure 16; click the hyperlink to see the effect! Once you click on the hyperlink, a pop up alert would appear as shown in figure 19 instead of navigating you to the linked environment/site.

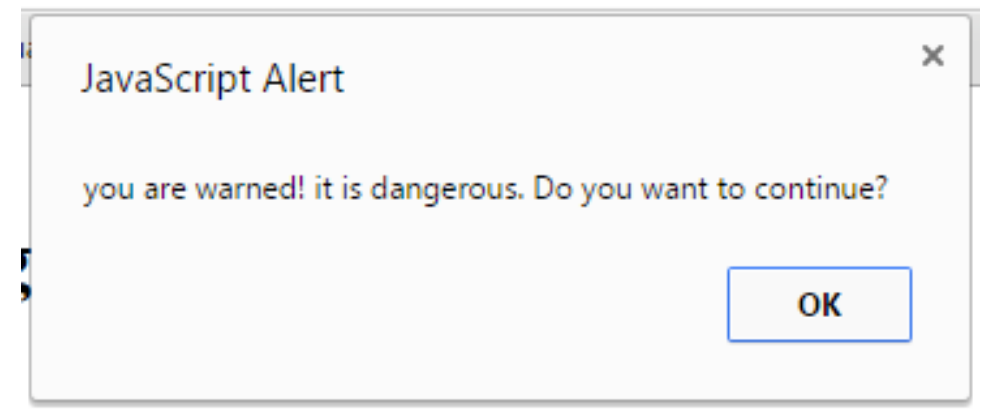

Figure 19

The above alert was created by the JavaScript code added to the html hyperlink opening tag. This approach is called the Inline Application. As you can see in figure 19, what was added as the JavaScript code was:

onclick="alert('you are warned! it is dangerous. Do you want to continue?');"

Please note that in the context of the above Inline JavaScript code; 'onclick' is the function key followed by an equal sign (=) then the defined function value in double inverted coma ("'). The actual defined function value is 'alert' while content of the alert warning is placed in brackets and inside a single qoatation marks with a semi column after the closing bracket. 


\section{International Journal of Research in English Education}

\subsection{Castigating Style Sheet (CSS3)}

CSS3 aplication in HTML is all about making the presentation of web pages content more stylish and pretty. It deals with the adjustment of font, color, border, and margins of HTML text and content. There are basically three ways of using (applying) CSS3 application in HTML: the 'In-line Application Method', the 'Internal Application Method' and the 'External Application Method.' The In-line application uses style, attributes, and values with equal sign, inverted coma, colum, and semi-colum signs with no space in-between (Style= "attributes:value"). The Internal Application Method on the other hand uses the style element, coly brackets, colum and semi-columsigns (<style ></style $>,\{\},:, ;)$ while the External Application Method uses only the coly brackets with colum and semi-colum signs ( \{\}$,:, ;)$. We shall demonstrating how these applications works with examples.

\subsubsection{The In-line Application of CSS3 in HTML}

This is done by adding the 'style' attributes and their defined values in the opening tag of html elements. $\langle\mathrm{P}\rangle\langle/ \mathrm{P}\rangle$ This for example is a html element for paragraph coding. The red tag is the opening tag of the element where the inline CSS3 can be applied. For example, the text content in figure 20A below is a HTML coded text while the content of figure 20B has the in-line application of CSS3 added. The added in-line application of the CSS3 code is highlighted in red fonts.

$<\mathrm{p}>$ I wish it rains today. It's been so hot these days and I find it difficult to work properly whenever the weather is heated. I have to get myself an air condition in the house so as to have an enabling working environment for myself whenever I am home $</ p>$
$<$ p style $=$ "color: green" $>$ I wish it rains today

It's been so hot these days and I find it difficult

to work properly whenever the weather is

heated. I have to get myself an air condition in

the house so as to have an enabling working

environment for myself whenever I am

home $</ \mathrm{p}>$

Figure 20B

Figure 20A

The CSS3 In-line applied in figure 20B would change the paragraph content to green as specified in the style attributes and value.

\subsubsection{The Internal Application of CSS3 in HTML}

This you can do by using the style element (<style $></$ style $>)$ inside the html head element after the closing tag of the html title element as shown in figure 21. 


\section{International Journal of Research in English Education}

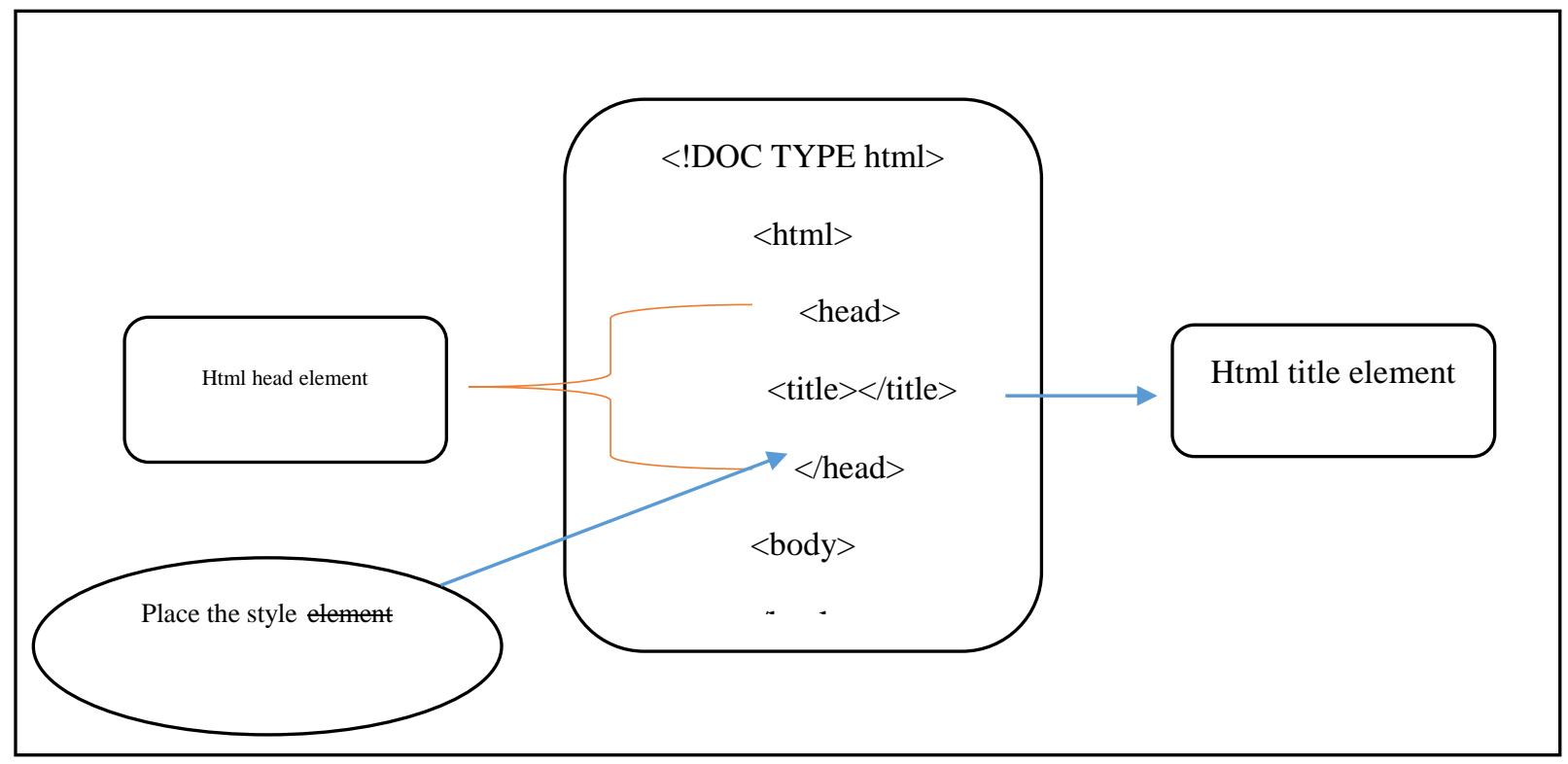

Figure 21

The above illustration is examplified in figure 22 showing how the internal application of CSS3 is applied in a HTML script file.

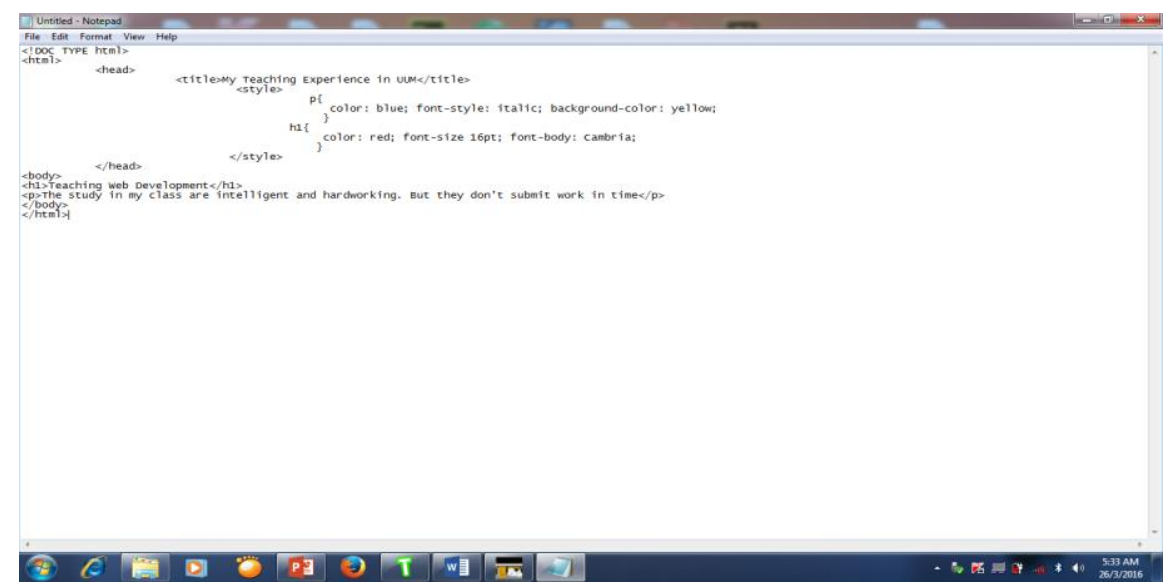

Figure 22

The content of the HTML script (Notepad) file in figure 22 is shown in figure 23 for clearity. The red font content is the internal CSS3 code applied. 


\section{International Journal of Research in English Education}

$<$ !DOC TYPE html $>$

$<$ html $>$

$<$ head $>$

$<$ title >My Teaching Experience in UUM $</$ title>

<style>

$\mathrm{p}\{$

color: blue; font-style: italic; background-color: yellow;

h1 \{

color: red; font-size 16pt; font-body: Cambria;

$</$ head $>$

$<$ body $>$

$<$ h1 $>$ Teaching Web Development $</$ h1 $>$

$<\mathrm{p}>$ The study in my class are intelligent and hardworking. But they don't submit work in time $</ \mathrm{p}>$

$</$ body $>$

$</$ html $>$

Figure 23

The applied CSS3 applied to the script in figure 23 would make the browser to present the content of the page in blue color, the font would appear in italic and the background color of the web page would appear in yellow color; the font size of the heading would be $16 \mathrm{pt}$ and in red color.

\subsubsection{The External Application of CSS3 in HTML Script}

The external application of CSS3 in html script is done by creating a separate file of CSS using the Notepad application and saving it in the same folder where the html file stored. While html script file carries the html extension (.html); CSS3 file should have an extension of 'dot css' (.css). All the styles intended for the web pages as contain in the html script file are to be scripted in css file separately. Then, link the two files (the html \& css files). The procedure of creating a CSS3 file is same with the procedure you used in creating your html file using the notepad application. Once you open the CSS3 file in the notepad environment you can write your CSS3 script directly. For example, the content in green font below can be scripted as the content of the script.

h1 \{

attribute: value; attribute: value; attribute: value;

$\mathrm{h} 2\{$

attribute: value; attribute: value; attribute: value;

\}

$\mathrm{p}\{$

attribute: value; attribute: value; attribute: value;

\}

$\mathrm{a}\{$ 


\title{
International Journal of Research in English Education
}

\author{
attribute: value; attribute: value; attribute: value; \\ \}
}

ul\{

attribute: value; attribute: value; attribute: value;

\}

\subsubsection{Saving the CSS3 External Script File and Linking It with the HTML Script File}

Click file in the menu of the notepad environment where you are writing the script. A pop up menu will appear, scroll down to 'save as' and click on it. Once you click 'save as' the 'save as' dialog box will appear; give it a name in the space provided, select the folder where you want to save and click save. The link for the two files should be created in the html file not the css file using the link tag (<link rel="stylesheet" href="name of the css file" >). The link tag should be created and placed in the head element under the closing tag of the title element.

\subsection{Content Management System (CMS)}

Content Management System is a software (web-based applicatoion) application that is designed to help in managing the content of a website. A content management system is developed using HTML, CSS, and JavaScript languages to provide template that can be used in building and publishing a website. This application has made it possible and easy for people with no knowledge of HTML, CSS, and JavaScript to be able to develop simple website. The system has two major elements: the Content Management Application (CMA) and Content Delivery Application (CDA).

CMA allows web authors and administrators to be able to create, modify, and delete the content of a website. The CDA allows the user to update the websites with the content created, deleted, or modified. Content Management systems have an inbuilt wizard that guide the user on how to use the available tools provided step-by-step to create, modify, or delete a website content and update the website with the changes done.

There are quite a lot of CMS existing in variety. Some are free (open source) and some are paid for. In choosing a CMS, one needs to consider the content intended to be published in the website. Would the content be made up of text only? Or text with images and videos would be a read only or interactive. The purpose of the website too needs to be considered. Some of the open source CMS include Drupal, Joomla, SilverStripe, WordPress, TextPattern, Weebly, and may more.

\section{Implications}

Most of the existing studies on ICT integration in educational practices as relate to teacher professional development lay emphasis on the need for ICT integration in teaching and learning while highlighting the potential benefits derivable from the use of technology in education. Though some studies went further to justify the need for the development of curriculum framework that can help prepare teachers toward the use of technology in education. Some of such studies as can be seen in the works Koehler and Mishra (2009) presented a framework (TPACK) suggesting the inclusion of technological knowledge (TK) as additional knowledge domain in teacher education and training. The study highlights the significance of the interplay of the additional knowledge domain with knowledge of pedagogy and subject content for the efective use of technology in educational practices. The framework is widely accepted and one significant aspect of the study is the gap it has established; the gap of identifying what exacly should make up the content of the additional knowledge domain (Tecknological Knowledge). Till this moment, there is no concensus as to what makes up the technological knopwledge domain. What was presented in this paper suggests some of the practical technological knowledge and skills needed that can form part of what is need to build the technological knowledge domain in addition to the basic knowledge of using the computer.

Including the knowledge and skills of using HTML, CSS, JavaScript, and CMS in the technological knowledge domain of teacher education would help to improve the prefessional competence of teachers in desiging and building effective instructional websites that can support educational practices. It would help to improve teacher performance in utilising the $21^{\text {st }}$ century teaching learning environment that has become more technology inclined (web-based). With these knowledge and skills, the teacher would would be able to engage his students in and outside the classroom environment using the web as teaching-learning environment. This would help to improve the students learning achievement. 


\section{International Journal of Research in English Education}

\section{Conclusion}

The need to engage students in the use of instructional websites is gradually becoming popular and necessary; particularly in handling the digital natives as learners to whom use of the web is an integral part of day to day life. Because of this development, there is the need for teachers to acquire the knowledge and skills of web design and development. As such, there is the need to integrate web design and development courses as one of the core courses in teacher education and training. This would enable pre-service teachers to acquire the knowledge and skills needed in the development of instructional websites. This paper identified knowledge of HTML, CSS, JavaScript, Content Management Systems, and principles of effective instructional website as the basic courses needed in developing the skills and competence needed by both teachers and pre-service teachers in the design and development of effective instructional websites that can be used to facilitate teaching and learning. The paper demonstrated how simple websites are created using the basic knowledge of HTML, CSS, and JavaScript.

\section{References}

Andrson, J. K. (2001). Internet Use among College Students: An Exploratory Study. Journal of American College Health, 50(1), 21-26. doi: 10.1080/07448480109595707

Castells, M. (2004). The Impact of the Internet on Society: a Global Perspectives. MIT Technology Review.

Grant, P., \& Basye, D. (2014). Personalized Learning: A Guide for Engaging Students with Technology. International Society for Technology in Education, Washington DC.

Koehler, M. I., \& Mishra, P. (2009). What Is Technological Pedagogical Content Knowledge? Contemporary Issues in Technology and Teacher Education, 9(1), 60-70.

Mikre, F. (2011). The Role of Information Communication Technologies in Education: Review Article with Emphasis on Computer and Internet. The Ethiopian Journal of Education and Science, 6(2), 1-16.

Proctor, P. et.al. (2005). Building a Better Delivery System: A New Engineering/Health Care Partner. National Academy of Science Press. Washington DC.

Schaaf, R. (2012). Does Digital Game-Based Improve Student-Time-on-Task Behavior and Engagement in Comparison to Alternative Instructional Strategy? Canadian Journal of Action Research, 13(1), 50-64.

Turner, L. (2005). 20 Technologies Skills Every Educator Should Have. The Journal, 33-11. Retrieved February 20, 2017, from http://thejournal.com/the/printarticle/?id=17325 